\title{
Indirect measurement of blood pressure during exercise testing can be misleading
}

\author{
BRIAN A GOULD,^ ROBERT S HORNUNG,† DOUGLAS G ALTMAN, \\ PETER M M CASHMAN, EDWARD B RAFTERY \\ From the Department of Cardiology and the Divisions of Clinical Sciences, Bioengineering, and Computing and \\ Statistics, Northwick Park Hospital and Clinical Research Centre, Harrow, Middlesex
}

SUMMARY Indirect blood pressures recorded with a random zero sphygmomanometer were compared with simultaneous intra-arterial blood pressures recorded with the Oxford system. Twenty five patients undertook a graded bicycle exercise test, cycling at workloads increasing from 41, 65, 114 , and $163 \mathrm{~W}$ ( 250 to 400,700 , and $1000 \mathrm{kpm}$ per min) with each grade being maintained for three minutes unless the exercise test was terminated earlier at the point of fatigue. Intra-arterial pressures were recorded continuously and indirect measurements made at steady state levels in the 30 seconds before each change in grade and immediately after the termination of the exercise protocol. The mean difference in systolic blood pressure at 5.5 minutes of exercise showed that the indirect measurement underestimated the direct measurement. Immediately after the termination of exercise the blood pressure fell precipitiously to a highly significant degree. For both systolic and diastolic pressures there was considerably individual variability.

These data confirm that indirect methods of blood pressure measurement during dynamic exercise testing are inaccurate and may provide misleading information.

Blood pressure is a continuous physiological variable, with considerable changes from beat to beat and minute to minute in response to numerous influences both external and internal to the individual. Single recordings using the indirect technique (mercury in glass manometer, arm cuff, and Korotkoff sounds) can provide only a rough estimate of the true values, although the degree of accuracy can be improved by taking the mean of repeated measurements. ${ }^{2}$ Comparisons of direct and indirect techniques ${ }^{3-6}$ have shown that considerable discrepancies can occur even when recording conditions are ideal. Indirect measurements in the exercising subject are likely to be even more inaccurate because of the movement of the subject, the high level of extraneous noise, and the likelihood of increased variability induced by the increasing respiratory effort, yet most of the available

Requests for reprints to Dr E B Raftery, Department of Cardiology, Northwick Park Hospital, Watford Road, Harrow, Middlesex HA1 3UJ.

Present addresses: ^Cairdiology Department, Green Bank Hospital, Green Bank Road, Plymouth, †Stobhill Hospital, Glasgow.

Accepted for publication 29 January 1985 information on the blood pressure response during exercise has been collected in this way. ${ }^{7-9}$ Some workers $^{7}$ y $^{10}$ have attempted to improve their accuracy by recording the blood pressure immediately after the cessation of exercise, but intra-arterial recording has shown that the blood pressure falls very rapidly at this time and may return to the baseline levels within 30 seconds (Fig. 1).1112

We report here the results of a formal comparison of direct and indirect recordings obtained at different grades of exercise and in the immediate postexercise period.

\section{Patients and methods}

Twenty five patients were recruited from the Harrow Hypertension Clinic; 11 were taking no medication and 14 were receiving antihypertensive treatment $(10$ patients were taking beta adrenoceptor blockers, of whom three were also taking prazosin, while the remaining four patients were taking prazosin alone). The group consisted of 19 men and six women with a mean age of 49 (range 23-66) years. All patients had a 


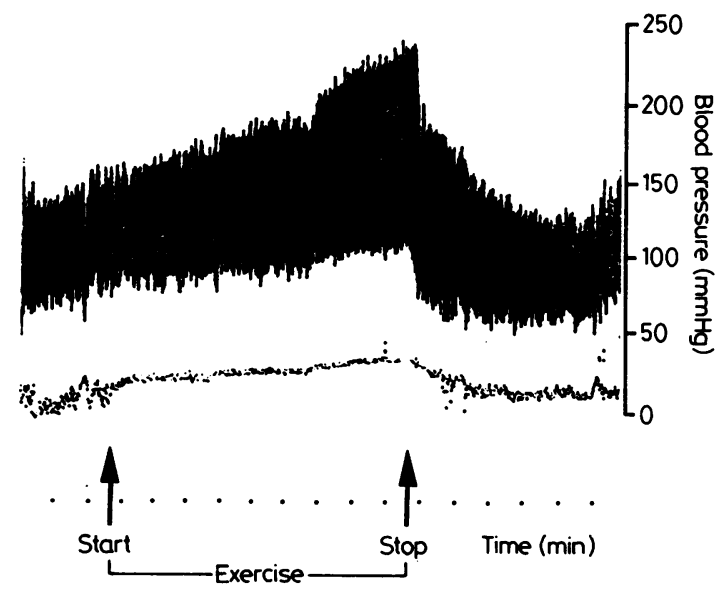

Fig. 1 Intra-arterial recording of one patient during bicycle exercise testing.

diagnosis of essential hypertension, having undergone routine testing to exclude secondary causes.

\section{BLOOD PRESSURE RECORDING}

Since indirect blood pressure was recorded from the dominant arm and direct pressure from the nondominant arm the pressures in the two arms were assessed independently by two observers using a random zero manometer attached by a $\mathrm{Y}$ tube to two cuffs. The cuffs were then interchanged and further measurements taken. The procedure was then repeated with the observers changing arms. The relation of arm circumference was also assessed and found not to influence the data (manuscript in preparation).

Each subject then underwent intra-arterial ambulatory blood pressure monitoring, a technique which has been fully described and evaluated elsewhere. 13-15 Patients attended hospital in the morning, before 1100 , for percutaneous insertion of the intra-arterial cannula into the brachial artery of the non-dominant arm. The blood pressure signal was measured with the Stott transducer-perfusion system and recorded on a Medilog I tape recorder (Oxford Medical Systems). This system has previously been validated and found to have a frequency response flat to $8 \mathrm{~Hz},,^{14}$ as well as being accurate in comparison with a Millar tipped catheter at varying heart rate. ${ }^{15}$

\section{EXERCISE TEST}

After insertion of the cannula, each patient undertook a bicycle exercise test using an Elema (type 369) bicycle. They were requested to cycle at workloads increasing from $40 \cdot 8,65 \cdot 2,114$, and $163 \mathrm{~W}(250,400$, 700 , and $1000 \mathrm{kpm}$ per min), each grade being maintained for three minutes or terminated earlier at the point of fatigue. The tests were carried out under standardised conditions with a constant laboratory temperature and at approximately the same time in the morning. Indirect blood pressures were recorded by one of two physicians in the last 30 seconds of each grade of exercise and immediately after exercise was stopped using a Hawksley random zero sphygmomanometer. ${ }^{16}$ For diastolic measurements Korotkoff phase $\mathrm{V}$ was used. The exact time the pressure was recorded was marked on the intra-arterial tape using an electrical event marker.

The indirect pressure was recorded from the dominant arm of each patient, which was extended over the handle bars, and supported by the observing physician and was at the same level as the intraarterial blood pressure transducer. The intra-arterial system was calibrated within 5 minutes of the exercise test.

\section{DATA ANALYSIS}

The tapes were replayed on a linear direct writing recorder (Watanabe) to check the signal quality and identify the event marks. A purpose built hybrid computer ${ }^{17}$ was used to digitise a half minute mean blood pressure corresponding to each electrical event mark. It was not possible to identify the exact direct beats corresponding to the indirect systolic and diastolic pressures, so we used the mean blood pressure over the 30 seconds during which the indirect pressure was recorded. This has been shown to agree closely with single systolic and diastolic beats. ${ }^{18}$ Figure 1 shows the rapid reduction of the blood pressure. In addition to this rapid fall in blood pressure there were fluctuations in pressure due to respiration, vasomotor activity, and other reflex activity. The only way this problem could be overcome would be to have an event made at the instants the cuff systolic and diastolic sounds were detected, so that a true beat by beat comparison could be made. Mistiming of the exact beat may lead to a significant error. We considered that the risk of mistiming estimating the exact beats was substantial and preferred the 30 second mean intra-arterial pressure.

The mean and standard deviation for each measurement were calculated as well as the mean difference (discrepancy) and the standard deviation and frequency distribution of between method differences, which were plotted in addition to a scatter plot. ${ }^{19}$ Paired $t$ tests were used to assess the mean differences between pairs of readings.

Numerous comparisons of resting indirect and direct arterial blood pressure measurements have been reported, ${ }^{3-6}$ but it was not our intention to repeat this work. Resting indirect blood pressure measurements were not made routinely, but 12 patients did have resting indirect and direct arterial 
Table 1 Mean discrepancy values in blood pressure measured by indirect and direct methods during dynamic bicycle exercise

\begin{tabular}{|c|c|c|c|c|c|c|c|c|c|c|}
\hline \multirow[t]{2}{*}{ Exercise time } & \multirow{2}{*}{$\begin{array}{l}\text { Recording } \\
\text { method }\end{array}$} & \multicolumn{7}{|c|}{ Blood pressure (mm $\mathrm{Hg}$ ) } & \multicolumn{2}{|c|}{ Heart rate } \\
\hline & & Mean & $S D$ & $n$ & $\begin{array}{l}\text { Mean difference } \\
\text { between methods }\end{array}$ & $S D$ of differences & $t$ value & $p$ value & Mean & $S D$ \\
\hline \multicolumn{11}{|c|}{ Systolic pressure } \\
\hline $\begin{array}{l}\text { Exercise (min) } \\
\text { At } 2.5\end{array}$ & \multirow{4}{*}{$\begin{array}{l}\text { Indirect } \\
\text { Direct } \\
\text { Indirect } \\
\text { Direct } \\
\text { Indirect } \\
\text { Direct } \\
\text { Indirect } \\
\text { Direct }\end{array}$} & \multirow{4}{*}{$\begin{array}{l}181 \\
196 \\
188 \\
204 \\
200 \\
215 \\
200 \\
217\end{array}$} & \multirow{4}{*}{$\begin{array}{l}29.4 \\
33.6 \\
36.5 \\
38.3 \\
35.1 \\
36.9 \\
37.8 \\
41.4\end{array}$} & 25 & -15 & 13: & -.8 & 0.001 & 90 & $17 \cdot 0$ \\
\hline At 5.5 & & & & 25 & -16 & $15 \cdot 2$ & $5 \cdot 3$ & 0.001 & 102 & 20.7 \\
\hline At 8.5 & & & & 13 & -15 & $12 \cdot 3$ & $4 \cdot 2$ & 0.001 & 123 & $26 \cdot 8$ \\
\hline After & & & & 25 & -18 & $18 \cdot 5$ & $4 \cdot 8$ & 0.001 & 114 & $32 \cdot 0$ \\
\hline \multicolumn{11}{|c|}{ Diastolic pressure } \\
\hline $\begin{array}{l}\text { Exercise (min): } \\
\text { At } 2.5\end{array}$ & \multirow{4}{*}{$\begin{array}{l}\text { Indirect } \\
\text { Direct } \\
\text { Indirect } \\
\text { Direct } \\
\text { Indirect } \\
\text { Direct } \\
\text { Indirect } \\
\text { Direct }\end{array}$} & \multirow{4}{*}{$\begin{array}{l}114 \\
110 \\
111 \\
113 \\
114 \\
116 \\
102 \\
116\end{array}$} & \multirow{4}{*}{$\begin{array}{l}19.6 \\
17.2 \\
21.0 \\
18.3 \\
23.2 \\
22.2 \\
19.8 \\
21.2\end{array}$} & 25 & 4 & $14 \cdot 1$ & $1 \cdot 2$ & 0.2 & & \\
\hline At 5.5 & & & & 25 & -2 & 12.9 & 0.9 & 0.5 & & \\
\hline At 8.5 & & & & 12 & 2 & 9.6 & 0.5 & 0.5 & & \\
\hline After & & & & 25 & -14 & $15 \cdot 4$ & $4 \cdot 7$ & 0.0001 & & \\
\hline
\end{tabular}

blood pressures compared at a similar time to the above study. These data have been used to compare the mean difference between the two techniques of blood pressure measurement at rest and during exercise. Replicated (that is, repeated) resting mean differences were obtained and an analysis of variance undertaken from which a pooled estimate of the mean difference and standard deviation was obtained. This was used to compare the mean differences between indirect and direct at rest, after 2.5, 5.5, and 8.5 minutes of exercise, and on cessation of exercise.

The intersubject variability was tested by calculating the variance ratio ( $\mathrm{F}$ test), and paired $t$ tests were used to compare the mean differences of average resting clinic blood pressure and intra-arterial blood pressure with those after 2.5 and 5.5 minutes of exercise.

\section{Results}

No significant differences were found between the left and right arm blood pressures of these patients with a mean difference of $<1 \mathrm{~mm} \mathrm{Hg}$ and standard errors of 0.69/0.45 $\mathrm{mm} \mathrm{Hg}$.

\section{COMPARISON OF INDIRECT AND DIRECT BLOOD PRESSURE}

Table 1 summarises the detailed results for $2.5,5.5$, and 8.5 minutes and postpeak exercise. Since these were similar, only plots for 2.5 minutes of exercise and postpeak exercise are included in Fig. 2 (the lines are the lines of identity). The overall trend was the same for each stage; indirect systolic pressures grossly underestimated intra-arterial pressure, but the diastolic pressures were similar with both techniques. For both systolic and diastolic pressures there was considerable individual variability.

\section{COMPARISON OF CLINIC INTRA-ARTERIAL BLOOD} PRESSURE DIFFERENCES AT REST AND DURING EXERCISE

The replicated readings of resting blood pressure differences between indirect and direct recordings were subjected to an analysis of variance. The mean differences and standard deviations were calculated for the 12 patients who had resting indirect and direct blood pressures (Table 2). Analysis of the intersubject variability at rest compared with exercise (Table 2) showed that the trend was towards wider differences and greater variability of the indirect method in relation to intra-arterial blood pressures during exercise compared with at rest.

\section{Discussion}

Despite the well known fluctuation of the blood pressure with exercise, measurement of rapidly changing blcod pressure using the standard indirect technique has been subjected to only limited critical validation. Under conditions of quiet supine rest the indirect cuff method compared with intra-arterial pressure has shown a wide range of differences, ${ }^{3-6}$ and this discrepancy might be expected to get worse when measurements are attempted during strenuous exercise. Apart from the obvious physical difficulties of recording 


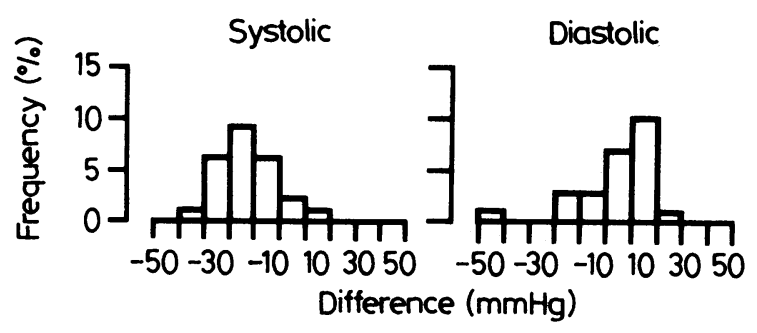

Systolic

Diastolic
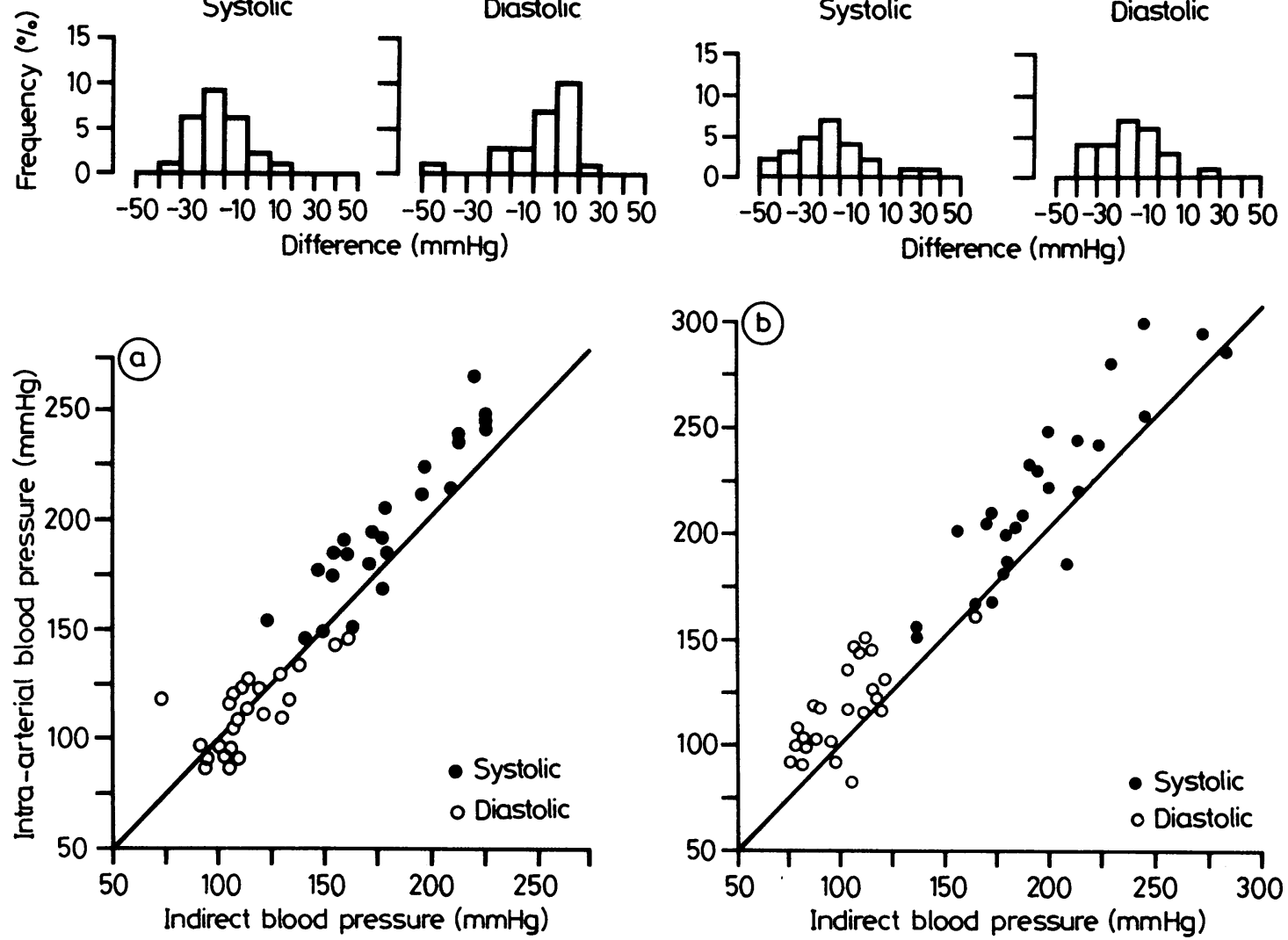

Fig. 2 Scatter plot and frequency histograms comparing indirect and intra-arterial blood pressures (a) at 2.5 minutes of exercise and (b) immediately after the end of exercise (postpeak). (a) $28 \%$ of systolic and $44 \%$ of diastolic indirect blood pressures and (b) $24 \%$ of systolic and 36\% of diastolic indirect blood pressures were within $10 \mathrm{~mm} \mathrm{Hg}$ of the intra-arterial blood pressures recorded.

indirect measurements during exercise, it is known that physiological changes in the cardiovascular system take place which may well affect the physical characteristics of the brachial artery and hence the intrinsic accuracy of the indirect technique.

The present study has confirmed the very rapid fall in blood pressure on cessation of exercise and has shown that during exercise the indirect systolic pressures consistently and significantly underestimate the intra-arterial pressures. The mean difference, ranging from 15 to $18 \mathrm{~mm} \mathrm{Hg}$, was slightly greater than previously reported in a similar comparison at rest when the mean difference was found to be $12 \mathrm{~mm} \mathrm{Hg} .{ }^{19}$

The mean discrepancy for diastolic pressures was

Table 2 Analysis of blood pressure data recorded by indirect and direct methods at rest, at 2.5, 5.5, and 8.5 mimutes of exercise, and after exercio

\begin{tabular}{|c|c|c|c|c|c|c|c|c|c|c|c|c|c|c|c|}
\hline \multirow{3}{*}{$\begin{array}{l}\text { Blood } \\
\text { pressure }\end{array}$} & \multicolumn{5}{|c|}{ Mean $(S D)$ difference between methods } & \multicolumn{10}{|c|}{ Statistical comparisons } \\
\hline & \multirow[t]{2}{*}{ Rest* $^{\star}$} & \multirow[t]{2}{*}{2.5} & \multirow[t]{2}{*}{$5 \cdot 5$} & \multirow[t]{2}{*}{$8 \cdot 5$} & \multirow[t]{2}{*}{ Postpeak } & \multicolumn{4}{|c|}{2.5 vs rest } & \multicolumn{4}{|c|}{5.5 vs rest } & \multicolumn{2}{|c|}{$\begin{array}{l}\text { Pospeak } \\
\text { rest }\end{array}$} \\
\hline & & & & & & $t \dagger$ & $\begin{array}{l}p \\
\text { value }\end{array}$ & $F \ddagger$ & $\begin{array}{l}p \\
\text { value }\end{array}$ & $t+$ & $\begin{array}{l}p \\
\text { value }\end{array}$ & $F \ddagger$ & $\begin{array}{l}p \\
\text { value }\end{array}$ & $F \ddagger$ & \\
\hline Systolic & $\begin{array}{l}0.8(12 \cdot 2) \\
(\mathrm{n}=12)\end{array}$ & $\begin{array}{l}-16 \cdot 7(15 \cdot 1) \\
(n=12)\end{array}$ & $\begin{array}{l}-16 \cdot 5(18 \cdot 8) \\
(\mathrm{n}=12)\end{array}$ & $\begin{array}{l}-15 \cdot 0(14 \cdot 0) \\
(n=7)\end{array}$ & $\begin{array}{l}-16.8(12 \cdot 3) \\
(n=12)\end{array}$ & $3 \cdot 13$ & 0.01 & 1.52 & 0.50 & 2.46 & 0.03 & $2 \cdot 36$ & 0.17 & 1.02 & \\
\hline Diastolic & $\begin{array}{l}-11 \cdot 3(9 \cdot 0) \\
(n=12)\end{array}$ & $\begin{array}{l}2 \cdot 4(18.4) \\
(n=12)\end{array}$ & $\begin{array}{l}-4.8(14.8) \\
(n=12)\end{array}$ & $\begin{array}{l}-5 \cdot 8(4 \cdot 4) \\
(n=6)\end{array}$ & $\begin{array}{l}-15 \cdot 7(12 \cdot 1) \\
(n=12)\end{array}$ & 1.40 & 0.19 & $4 \cdot 15$ & 0.03 & 2.81 & 0.02 & 2.69 & $0 \cdot 12$ & 1.80 & \\
\hline
\end{tabular}

^From analysis of variance using two or three observations per subject.

†Paired $t$ test comparing differences in blood pressure using indirect and direct methods.

$¥$ Two sided F test comparing intersubject variability in differences in blood pressure with two methods. 
not as large as that for systolic pressures, individual differences ranging from -14 to $+4 \mathrm{~mm} \mathrm{Hg}$. The indirect diastolic pressures were approximately the same on average as direct pressures at $2.5,5.5$, and 8.5 minutes of exercise, although there was considerable variation for individual subjects.

The large discrepancies (mean $-18 /-14 \mathrm{~mm} \mathrm{Hg}$ ) which were found in the postexercise period can be explained by the method of data collection. A single indirect pressure was recorded and compared with a 30 second mean intra-arterial pressure recorded while the indirect pressure was measured. Since intraarterial pressures at the end of exercise fall rapidly this mean was taken on a downward pressure slope. Workers using the postexercise pressure with the indirect technique have the same problem, and it would seem to be impossible to measure the blood pressure using a sphygmomanometer at the same point of the slope for the same individual on different occasions or in different individuals at the same point of the falling pressure slope. Comparison of the indirect and intra-arterial blood pressure mean difference at rest and during exercise shows a trend to higher systolic mean differences during exercise, and the individual differences were more variable.

These data suggest that it is necessary to perform intra-arterial recordings during all exercise tests. For clinical purposes this is obviously impracticable, but we would advise caution in relying on such measurements. We recommend using intra-arterial recordings, for research purposes, where blood pressure measurements are important.

\section{References}

1 Diehl HS, Lees HD. The variability of blood pressure. Arch Intern Med 1929; 44: 229-37.

2 Dunne JF. Variation of blood-pressure in untreated hypertensive outpatients. Lancet 1969; i: 391-2.

3 Steele JM. Comparison of simultaneous indirect (auscultatory) and direct (intra-arterial) measurements of arterial pressure in man. Fournal of the Mount Sinai Hospital 1941-1942; 8: 1042-50.

4 Ragan C, Bordley J. The accuracy of clinical measurements of arterial blood pressure. Bulletin of the Fohns Hopkins Hospital 1941; 69: 504-28.
5 Holland WW, Humerfeld S. Measurement of blood: pressure: comparison of intra-arterial and cuff values. $\mathrm{Br}$ Med f 1964; ii: 1241-3.

6 Raftery EB, Ward AP. The indirect method of recording. blood pressure. Cardiooasc Res 1968; 2: 210-8.

7 Korner P. The normal human blood pressure during and after exercise, with some related observations on changes. in the heart rate and the blood flow in the limbs. Aust $\mathcal{F}$ Exp Biol Med Sci 1952; 30: 375-84.

8 Wong HO, Kasser IS, Brucer RA. Impaired maximal exercise performance with hypertensive cardiovascular disease. Circulation 1969; 39: 633-8.

9 Irving JB, Bruce RA, De Rouen TA. Variations in and significance of systolic pressure during maximal exercise (treadmill) testing. Am $\mathcal{F}$ Cardiol 1977; 39: 841-8.

10 Norris AH, Shock NW, Yiengst MJ. Age changes in heart rate and blood pressure responses to tilting and standardized exercise. Circulation 1953; 8: 521-6.

11 Millar-Craig MW, Mann S, Balasubramanian V, Lahiri A, Raftery EB. Continuous recording of intra-arterial blood pressure during graded bicycle ergometry and stair climbing in essential hypertension. Biotelem Patient Monit 1981; 8: 33-46.

12 Balasubramanian V, Mann S, Millar-Craig MW, Raftery EB. Effect of labetalol in hypertension during exercise and postural changes. Br $\mathcal{F}$ Clin Pharmacol 1979; 8 (suppl): 95s-100s.

13 Bevan AT, Honour AJ, Stott FH. Direct arterial pressure recording in unrestricted man. Clin Sci 1969; 36: $329-44$.

14 Millar-Craig MW, Hawes D, Whittington J. New system for recording ambulatory blood pressure in man. Med Biol Eng Comput 1978; 16: 727-31.

15 Millar-Craig MW. Ambulatory intra-arterial blood pressure in essential hypertension. University of London, 1979. MD Thesis.

16 Wright BM, Dore CF. A random-zero sphygmomanometer. Lancet 1970; i: 337-8.

17 Cashman PMM, Stott FD, Millar-Craig MW. Hybrid system for fast data reduction on long-term blood pressure recordings. Med Biol Eng Comput 1979; 17: 629-35.

18 Gould BA, Hornung RS, Kieso HA, Altman DG, Cashman PMM, Raftery EB. A validation of home blood pressures, the Remler M200 and Avionics 1978 pressurometer with clinic and intra-arterial ambulatory blood pressure measurements. In: Stott FD, Wright SL, Raftery DB, Clement DL, eds. Proceedings of the 4th international symposium on ambulatory monitoring. Ghent: Academic Press, 1981: 489.

19 Altman DG, Bland JM. Measurements in medicine: the analysis of method comparison studies. Statistician 1983; 32: 307-17. 